\title{
Determination of Residues Levels of Seven Pesticides in Tomatoes Samples Taken from Three Markets in Khartoum State, Sudan
}

\author{
Ahmed $^{* 1}$, M.A. Hammad, Azhari O. Abdelbagi ${ }^{1}$, Abd Elaziz S.A. Ishag ${ }^{1}$, Asma Ahmed ${ }^{1}$ \\ and Mark D. Laing ${ }^{2}$
}

\begin{abstract}
A total of 9 fresh tomato samples were collected from domestic markets in Khartoum State, Sudan and analyzed for the presence of seven pesticide residues. Sample collection and preparation were carried out using standard procedures.The concentrations of pesticide residues were determined by gas chromatography equipped with a flame ionization detector (GC-FID) after extraction with acetone in presence of dichloromethane, and cleanup on solid phase extraction cartridges. Recovery studies were performed at $0.5 \mathrm{mg} \mathrm{kg}-1$ of each pesticide. Levels recovery obtained ranged between $67.5-97.2 \%$. The limits of detection of the method ranged between 0.00122 and $0.00433 \mathrm{mg} \mathrm{kg}$ - 1 for different pesticides studied. Out of nine tomato fruit samples, eight were contaminated with one or more of the pesticides. The highest concentration of a pesticide residue was $13.88 \mathrm{mg} \mathrm{kg} \mathrm{-1} \mathrm{of} \mathrm{beta} \mathrm{endosulfan} \mathrm{from} \mathrm{Sample}$ 2 collected from the Omdurman central market. The residue values were higher than the maximum residue levels (FAO/WHO, 2009) for all measured pesticides except deltamethrin.
\end{abstract}

Keywords - Tomato, pesticide residues, GC-FID.

\section{INTRODUCTION}

Tomato (Lycopersicon esculentum L.) belongs to the family Solanaceae and is an important vegetable crop. It is consumed fresh in salads or is processed into juice, soup, pickles, ketchup and paste. Fresh and processed tomato products are important ingredients in cooking. Tomato fruit are a daily component of Sudanese meals [1].

Chemical control of crop pests is well established in many countries including Sudan, where insecticide spraying started in the Gezira scheme in 1945 for the control of cotton insects pests [2]. Numerous agrochemicals are used in agriculture: herbicides, insecticides, fungicides, bactericides, rodenticides, nematicides, acaricides, etc. The use of pesticides for

Manuscript received August 9, 2014. (Write the date on which you submitted your paper for review.) This work was supported in part by the U.S. Department of Commerce under Grant BS123456 (sponsor and financial support acknowledgment goes here)

Azhari O. Abdelbagi, Abd Elaziz S.A. Ishag and Asma Ahmed are with the Dept. of Crop Protection, Faculty of Agric., University of Khartoum, P O Box 321, Khartoum, Sudan.

Mark D. Laing was with ]Discipline of Plant Pathology, School of Agricultural, Earth and Environmental Sciences,University of KwaZulu-Natal,Pietermartizburg, Postal Code 3201, South Africa.

*Corresponding author; Ahmed Mohammed Ali Hammad, Dept. of Crop Protection, Faculty of Agric., University of Khartoum, P O Box 321, Khartoum, Sudan. (e-mail: Ahmed7399@yahoo.com) prevention or control of crop pests leaves pesticide residues in and on food crops, which may result in food contamination, which may affect human or animal health [3]. Contamination of tomato fruit with pesticide residues can be high because tomato crops may be sprayed with pesticides every 3-7 days from the first week after seed germination to the last picking [4]. In one study, approximately $20 \%$ of interviewed vegetable farmers in central Sudan did not know about safety periods, used a number of insecticides at higher than registered doses, sometimes used pesticides registered for aerial application on cotton alone on food crops, and ignored pre-harvest intervals [5]. The pesticides most commonly used in Sudan belong to the chemical classes of organophosphate, organochlorine, pyrethroid, carbamate and neonicotinoid. Insecticides belonging to these chemical groups have been found to have be used on tomato crops by Sudanese farmers [6]. To evaluate food quality and to avoid risks to human health, governments and international organizations regulate the use of pesticides by setting the maximum residue levels (MRLs) in foods [7, 8]. The low level of some MRLs has led to research to improve the limits of detection of key pesticides, using rapidly evolving analytical methods for their analysis.

To assess the many pesticides and their degradation products in tomato samples, multi-residue extraction methods (MRMs) and separation techniques using gas chromatography (GC) and liquid chromatography (LC) are required $[9,10]$. Pesticide residues have been analyzed by gas chromatography with different detectors, such as nitrogen phosphorus (NPD) [11] or electron-capture detectors (ECD) and flame ionization detectors (FID) [12] for organonitrogen and organophosphate or organohalogen pesticides.

The foregoing literature reviews of pesticide residues in food and vegetables in the developing countries such as Sudan in the tomato fruits are very rare, particularly in Sudan there are a very few studies measured pesticide residues in tomato fruits on this field. In additional, the distribution of fatal diseases and carcinogenic and similar diseases due to the contaminants enhanced us to do the present study. Our finding is the first profound study of measuring large number of pesticide residues in tomato fruits collected from consumer's famous markets and sold across the Khartoum State, Sudan.

The aim of this study was to determine the residue levels of seven selected pesticides in tomato fruit sourced from markets in central Khartoum. The levels of residues were determined by 
gas chromatography coupled with a flame ionization detector (FID). The pesticides were chosen for analysis based on their common usage in Sudan and the availability of pure samples of seven pesticides to be used as standards.

\section{PROCEDURE FOR PAPER SUBMISSION}

\section{A. Sampling}

Analysis of different pesticide residues in tomato fruits samples was carried out according to the methods of Specht and Winkleman [13] and Pang et al., [14] with minor modifications. Fresh tomato fruit were sourced from three fresh produce markets (Khartoum, Omdurman and Bahri) in central Sudan. From each market three samples were taken randomly $(1 \mathrm{~kg}$ for each sample). Each sample was divided into three subsamples. Fruits of $1000 \mathrm{gm}$ were finely chopped using a pre-cleaned knife and mixed thoroughly to homogenise the samples prior to extraction.

\section{B. Extraction and Partitioning}

Extraction was done according to the methods of Specht and Winkleman [13] and Pang et al.[14] Forty grams per sample were blended with $5 \mathrm{ml}$ water and $100 \mathrm{ml}$ acetone in a high speed chemical resistance blender (National Analytical Corporation, Mumbai, India) for two minutes. The extract was collected in an Erlenmeyer flask and filtered through a fast rate filter paper (Whatman no. 1) in a Buchner funnel. The Erlenmeyer flask was rinsed with a little water and cleaned with acetone and the extract was filtered. The combined filtrates were collected in an Erlenmeyer flask for partitioning.

Extracts from each sample were transformed into a $500 \mathrm{ml}$ separation funnel. Fifty $\mathrm{ml}$ of dichloromethane and $10 \mathrm{ml}$ of saturated $\mathrm{NaCl}$ solution were added. The mixures were carefully shaken for 2 minutes with an open top to reduce pressure, and left to stand for 10 minutes to allow separation of layers. The organic layer was collected and then re-extracted with $50 \mathrm{ml}$ dichloromethane. The combined extracts of dichloromethane were filtered through cotton wool and mixed with $25 \mathrm{gm}$ of anhydrous $\mathrm{Na}_{2} \mathrm{SO}_{4}$, which was added to improve the extraction of polar pesticides and for its moisture absorbing ability.The products were then collected in $500 \mathrm{ml}$ round-bottom flasks. Extracts were again re-filtered through cotton wool and a $3 \mathrm{~cm}$ layer of anhydrous $\mathrm{Na}_{2} \mathrm{SO}_{4}$ sulphate in a separation funnel. The solvent was removed to dryness by a rotary evaporator (Buchi, Postfach, Switzerland) operating under vacuum at a temperature of $40^{\circ} \mathrm{C}$. Dried extracts were dissolved in $10 \mathrm{ml}$ of hexane and kept in closed vials at $-10^{\circ} \mathrm{C}$ for clean-up and pesticide residue analysis.

\section{Cleanup}

Sample cleanup followed the the methods of Specht and Winkleman [13] and Pang et al. [14] Sample cleanup was done using a solid phase extraction (SPE) column containing Florisil ${ }^{\circledR}$ and anhydrous $\mathrm{Na}_{2} \mathrm{SO}_{4}$. The column was first rinsed with a few $\mathrm{ml}$ of hexane. Extracts from each sample were added as soon as the hexane dried in the top of the Florisil@ layer and was then eluted by a $200 \mathrm{ml}$ of toluene:acetone in a 19:1 mixture. The elutes were concentrated to dryness by rotary evaporation. The dry powder was dissolved in $10 \mathrm{ml}$ of hexane, transferred to a $10 \mathrm{ml}$ volumetric flask and stored at $-10^{\circ} \mathrm{C}$ for subsequent residue analysis by GC-FID.

\section{Chemical and Reagents}

Technical grade pesticide standards were used for standardizations. Analytical standards of malathion, atrazine, chlorpyrifos, alpha and beta endosulfan, pendimethalin and deltamethrin (ca 99\% pure) were obtained from the Plant Protection Directory (Ministry of Agriculture, Bahri, Sudan). The above mentioned standards were stored in a freezer at $-10^{\circ} \mathrm{C}$. All solvents used were of analytical grade or similar quality. The solvents used acetone $\left(\mathrm{C}_{3} \mathrm{H}_{6} \mathrm{O}\right)$, dichloromethane $\left(\mathrm{CH}_{2} \mathrm{Cl}_{2}\right)$ and N-hexane $\left(\mathrm{C}_{6} \mathrm{H}_{6}\right)$ ) were HPLC grade (Scharlau, Spain). The toluene used $\left(\mathrm{C}_{6} \mathrm{H}_{5}-\mathrm{CH}_{3}\right)$ was analar grade. Other reagents like anhydrous $\left(\mathrm{Na}_{2} \mathrm{SO}_{4}\right)$, Florisil@ (60-100) mesh and sodium chloride $(\mathrm{NaCl})$ were purchased in Khartoum, Sudan.

\section{E. Chromatographic Instrumentation}

The Gas chromatography instrument (Shimadzu Model -2010, Japan), was fitted with a DB-5 (5\% phenylmethylpolysiloxane) capillary column $(30 \mathrm{~m} \times 0.25 \mathrm{~mm}$ i.d., $0.25 \mu \mathrm{m}$ film thickness), coupled with a flame ionization detector (FID), was employed under the following operating conditions: injection temperature of $280^{\circ} \mathrm{C}$; FID temperature of $300^{\circ} \mathrm{C}$; column temperature of $250^{\circ} \mathrm{C} ; \mathrm{N}_{2}$ flow rate at $1.5 \mathrm{ml}$ $\min ^{-1}$ as the carrier gas; the $\mathrm{N}_{2}$ /air makeup gas flow rate was 30 $\mathrm{ml} \mathrm{min}^{-1}$; and splitless injection with the opening of the splitter $0.5 \mathrm{~min}$ after injection. The column temperature was started at $80^{\circ} \mathrm{C}$ for $1 \mathrm{~min}$, and then was increased to $150^{\circ} \mathrm{C}$ at a rate of $15^{\circ} \mathrm{C} \mathrm{min}{ }^{-1}$, followed by a final increase to $250^{\circ} \mathrm{C}$ at a rate of $10^{\circ} \mathrm{C} \mathrm{m^{-1 }}$ until the end of the sample analysis. The total retention time was $40 \mathrm{~min}$. For all samples the injection volume was $1 \mu \mathrm{L}$.

\section{F. Preparation of Standard Solutions of Pure Pesticides}

Technical standards solutions $\left(2 \mathrm{mg} \mathrm{ml}^{-1}\right)$ of malathion, atrazine, chlorpyrifos, alpha and beta endosulfan, pendimethalin and deltamethrin were made by dissolving $20 \mathrm{mg}$ from each of the analytical standards in $10 \mathrm{ml}$ hexane. Then three concentrations of the standard solution of each pesticide were prepared. These were stored in the dark at $4{ }^{\circ} \mathrm{C}$ in order to be used to create calibration curves [15, 16] (Fig. 1 and 2).

\section{G. Pesticide Recovery}

In order to check the efficiency of the experimental methods, pesticide recovery from tomatoes was evaluated with "spiked" samples. A single fresh tomato sample was injected with $0.5 \mathrm{mg}$ $\mathrm{kg}^{-1}$ of each mentioned pesticides. The extraction and clean-up methods were as discussed above. Recovery levels ranged between 67.5-97.2\% (Table 1).

The concentrations of the individual pesticide residues in tomato samples are presented in Table 2.The concentration of pesticide residues were determined using external calibration and the formula below: Where:

Concentration in $\mathrm{mg} \mathrm{kg}^{-1}=\quad=\mathrm{ABV}_{\mathrm{t}} / \mathrm{V}_{\mathrm{i}} \mathrm{W}_{\mathrm{s}}$

$A=$ response factor (1/slope from calibration curve)

$\mathrm{B}=$ peak area

$\mathrm{V}_{\mathrm{t}}=$ extract volume in $\mu \mathrm{L}$ 
$\mathrm{V}_{\mathrm{i}}=$ volume injected in $\mu \mathrm{L}$

$\mathrm{W}_{\mathrm{s}}=$ weight of tomato sample $(\mathrm{kg})$

\section{RESULTS AND DISCUSSION}

Gas chromatographic (GC) methods are suitable for the separation and quantitative determination of compounds that are volatile or semi-volatile and thermally stable at the temperature of the measurement. A multi-residue method was selected for the detection of various pesticide residues in tomato samples collected from different locations. The limit of detection (LOD) of the method (sensitivity) for malathion, atrazine, chlorpyrifos, alpha and beta endosulfan pendimethalin and deltamethrin were determined from the signal-to-signal ratio using the equation:

$\mathrm{LOD}=3 * \mathrm{SD}$ (standard deviation) of intercept/Slope

The LODs were calculated for all mentioned pesticides and ranged between 0.00122 and $0.00433 \mathrm{mg} \mathrm{kg}^{-1}$. The RSD values (\%), which are the ratio between the standard deviation and the mean concentration found in the samples, [17] were between 1.3 and $4.3 \%$.The LODs and RSDs are shown in Table 1. Pesticide recovery levels were calculated by comparison with the standard solutions.

A total of nine tomato fruit samples collected from three major markets in Khartoum State (Sudan) were analyzed. The tomato fruit samples were contaminated with various pesticides residues, including deltamethrin, atrazine, malathion, chlorpyrifos, pendimethalin and beta endosulfan. Out of nine tomato fruit samples, eight were contaminated with one or more of these pesticides. In tomatoes from the Bahri central market (Sample 1, 2 and 3), chlorpyrifos, malathion, and malathion degradation residues were found at levels of 6.23, 7.66, and $7.40 \mathrm{mg} \mathrm{kg}^{-1}$, respectively. Two of the tomato samples from the Khartoum central market (Sample 4 and 5) were contaminated with malathion at levels of 7.33 and $7.6 \mathrm{mg} \mathrm{kg}^{-1}$. No pesticide residues were detected in Sample 6. Samples obtained from the Omdurman central market (Sample 7, 8 and 9) contained atrazine and malathion residues in Sample 7 format levels of 1.53 and $7.55 \mathrm{mg} \mathrm{kg}^{-1}$, malathion, deltamethrin and beta endosulfan residues in Sample 8 format levels of 7.58, 0.14 and $13.88 \mathrm{mg} \mathrm{kg}^{-1}$, and malathion and deltamethrin residues in Sample 9 at levels of 7.53 and $0.021 \mathrm{mg} \mathrm{kg}^{-1}$, respectively. The highest concentration of pesticide residue was $13.88 \mathrm{mg} \mathrm{kg}^{-1}$ of beta endosulfan found in Sample 8 collected from the Omdurman central market. The positive residue values measured in the tomato samples were higher than the maximum residue levels established by either Codex Alimentarius (FAO/WHO, 2009) or the European Union (EU) for all measured pesticides except deltamethrin. Furthermore, endosulfan and atrazine are not registered in Sudan for use on tomatoes. Their presence in tomatoes indicates misuse of pesticides by Sudanese farmers. These results are similar to other studies on residues in tomato fruit but the levels of the residues found were higher than those reported by others [18, $19,20,21]$.

TABLE 1: RETENTION TIME, R2, LOD, RECOVERY (THREE REPLICATES) AND RSD FOR PESTICIDES SCREENED FOR TOMATO FRUIT SAMPLES BY GC-FID.

\begin{tabular}{lllllll}
\hline Pesticide names & Retention time $(\mathrm{min})$ & Beak Area & $\mathrm{R}^{2}$ & LOD $\left(\mathrm{mgkg}^{1}\right)$ & Recovery $(\%)$ & RSD\% \\
\hline deltamethrin & 8.938 & 150627.4 & 0.6882 & 0.00142 & 67.52 & 1.32 \\
atrazine & 25.114 & 22079.5 & 0.9080 & 0.00331 & 72.34 & 3.46 \\
malathion & 30.367 & 16794.4 & 0.8994 & 0.00433 & 97.23 & 3.64 \\
chlorpyrifos & 30.980 & 37474.5 & 0.8016 & 0.00122 & 92.67 & 4.28 \\
pendimethalin & 32.744 & 58462.9 & 0.9920 & 0.00412 & 84.53 & 1.78 \\
Alpha endosulfan & 35.027 & 8362.6 & 0.8272 & 0.00126 & 95.22 & 3.24 \\
beta endosulfan & 38.357 & 3782.7 & 0.8975 & 0.00122 & 94.86 & 3.75 \\
\hline
\end{tabular}

LOD; limit of detection, R2; regression coefficient, RSD; relative standard deviation

TABLE 2: CONCENTRATIONS AND MRLS OF FIVE PESTICIDE RESIDUES IN TOMATO FRUIT SAMPLES COLLECTED FROM DIFFERENT LOCATIONS (THREE REPLICATES OF EACH SAMPLE)

\begin{tabular}{|c|c|c|c|}
\hline Location and sample number & Pesticide names & $\begin{array}{l}\text { Maximum residue levels (MRLs) } \mathrm{mg} \\
\mathrm{kg}-1\end{array}$ & Average of pesticide residues (mg kg-1) \\
\hline \multirow{5}{*}{$\begin{array}{l}\text { Bahri central market } 1 \\
,,,,,,,,,,,,,, 22 \\
,,,,,,,,,,,,,,,, 23 \\
\text { Khartoum central market } 4 \\
,,,,,,,,,,,,,,, \% 5\end{array}$} & malathion & 0.5 & 7.66 \\
\hline & chlorpyrifos & 0.5 & 6.23 \\
\hline & malathion & 0.5 & 7.40 \\
\hline & malathion & 0.5 & 7.33 \\
\hline & malathion & 0.5 & 7.6 \\
\hline \multirow{3}{*}{$\begin{array}{l},,,,,,,,,,,,,,,, " 6 \\
\text { Omdurman Central Market } 7\end{array}$} & ND & - & - \\
\hline & atrazine & 0.5 & 1.53 \\
\hline & malathion & 0.5 & 7.55 \\
\hline \multirow{3}{*}{,,,,,,,,,,,,,,,,,,,,,, 8} & malathion & 0.5 & 7.58 \\
\hline & deltamethrin & 0.3 & 0.14 \\
\hline & beta endosulfan & 0.5 & 13.88 \\
\hline \multirow[t]{2}{*}{,,,,,,,,,,,,,,,,,,,,$_{9}$} & malathion & 0.5 & 7.53 \\
\hline & deltamethrin & 0.3 & 0.021 \\
\hline
\end{tabular}

ND: not detected 


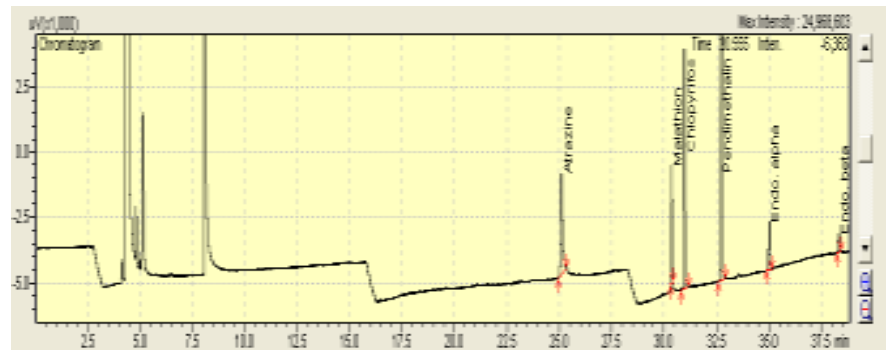

Fig 1. Chromatogram of the standard pesticides (mixtures of malathion, atrazine, chlorpyrifos, endosulfan alpha and beta, pendimethalin) by GC-FID.

The operation condition of GC: injection temperature of $280^{\circ} \mathrm{C}$; FID temperature of $300^{\circ} \mathrm{C}$; column temperature of $250^{\circ} \mathrm{C}$; $\mathrm{N} 2$ flow rate at $1.5 \mathrm{ml} \mathrm{min}-1$ as the carrier gas; the N2/air makeup gas flow rate was $30 \mathrm{ml} \mathrm{min-1;} \mathrm{and} \mathrm{splitless}$ injection with the opening of the splitter $0.5 \mathrm{~min}$ after injection.

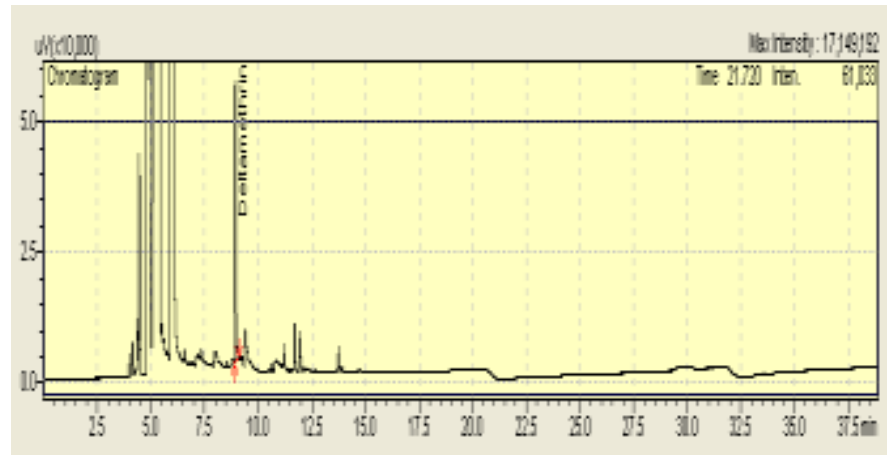

Fig 2. Chromatogram of the standard deltamethrin by GC-FID.

The operation condition of GC: injection temperature of $280^{\circ} \mathrm{C}$; FID temperature of $300^{\circ} \mathrm{C}$; column temperature of $250^{\circ} \mathrm{C}$; $\mathrm{N} 2$ flow rate at $1.5 \mathrm{ml} \mathrm{min}-1$ as the carrier gas; the N2/air makeup gas flow rate was $30 \mathrm{ml}$ min-1; and splitless injection with the opening of the splitter $0.5 \mathrm{~min}$ after injection.

\section{CONCLUSION}

The questioned farmers never take care and/or have no knowledge about safety period and pesticides residues. Our findings stated that out of nine tomato fruits samples eight of them were contaminated with different pesticides groups. However, more extension work are needed to knowledge the farmers of safety period, and how and when to use pesticides.

\section{ACKNOWLEDGMENT}

The authors would like to thank Shambat Central Laboratory Manager for provided GC analysis.

\section{REFERENCES}

[1] Ahmed, E.A.; Nourai, A.H.; Ali, G.H.M.; Dinnar, H.M.A.: Acta Horticulturae 1984, 143, 59.

[2] Farah, S.M.; Abdel Rahaman, A.A. Annual Report of the Gezira Research Station and Substations, Khartoum, Sudan, 1988, p 38.

[3] European Commission. Off J. Eur. Union, 2005, L70, 1.

[4] Abdelrahman, A.A. ICIPE Sciences Press, Nairobi, Kenya, 1994, p 33

[5] Dabrawski, Z.T. Science Press, Nairobi, Kenya, 1994, p 5, 12.

[6] Albadri, A.E.A.; Elbashir, A.A.; Ahmed, H.E.; Mihaina, I.A.M.; Aboul-Enein, H.Y. Food Anal. Methods 2012, 5, 1296.
http://www.codexalimentarius.net/pesters/data/index.html?lang=es./(Ac cessed 4 Sep., 2013)

[7] Rodríguez, A.S.; María, I.A.; Valenzuela, M.I.A.; Díez, N.M de la Peña, A.M.; Díaz, T.G. Analytical Methods 2012, 4, 2543.

[8] Luke, M.A. Froberg, J.E.; Masumoto, H.T. Assoc. Off. Anal. Chem.1975, $58,10$.

[9] Fernandez-Alba, A.R.; Valverde, A.; Ag€uera A.; Contreras, M.: J. Chromatogr. 1994, A 686, 263.

[10] Pérez, R.A.; Sánchez-Brunete, C.; Miguel, E.; Tadeo, J.L. J. Agric. Food Chem. 1998, 46, 1864.

[11] Synder, J.L.; Grob, R.L.; McNally, M.E.; Oostdyk, T.S. Journal Environmental Science and Health 1994, A29, 1801.

[12] Specht, W.; Winkleman. Pesticides Commission, Hamburg, Germany, 1994, pp. 384.

[13] Pang, G.F.; Cao, Y.Z.; Fan, C.L.; Zhang J.J.; Li, X.M. Journal of AOAC International 1999, 82,186.

[14] Hill, A. European Community:" $2^{\text {nd }}$ ed. Environmental Agency; Brussels, Belgium, 2000, p30.

[15] Subhash, C.; Mahindrakar, N.; Anil, L.; Shinde, P. International Journal of Chemical Technology and Research 2010, 2, 908.

[16] Islam, S.; Afrin, N.; Hossain, M.S.; Nahar, N.; Mosihuzzaman, M.; Iqbal, M. Am. J. Environ. Sci. 2009, 5 (3), 325.

[17] Jayakrishnan, S.D.; Singh A.K.; Pachauri, J.P. Bull. Environ. Contam. Toxicol 2005, 75, 324.

[18] Tahany, A.; Nasr N.; Hend, M. American-Eurasian Journal of Toxicological Sciences 2011, 3 (3), 213.

[19] Chauhan, R.M.; Kumari, B.S. Bull. Environ. Contam. Toxicol. 2012, 88, 352.

[20] Elbashir, A.A.; Albadri, A.E.A.; Ahmed, H.E. Focusing on Modern Food Industry (FMFI) 2013, 2(2), 103. 